\title{
EDUARDO CABALLERO CALDERÓN Y EDICIONES GUADARRAMA: EDICIÓN Y VISIBILIDAD LITERARIA ENTRE COLOMBIA Y ESPAÑA, 1954-1960 ${ }^{1}$
}

\author{
Juan David Murillo Sandoval \\ Instituto Caro y Cuervo \\ Bogotá, Colombia \\ juan.david.murillo.s@gmail.com
}

\section{RESUMEN / ABSTRACT}

Este artículo estudia el trabajo editorial del escritor colombiano Eduardo Caballero Calderón en Guadarrama Ediciones, editorial que fundó en Madrid en 1954, en compañía del editor español Manuel Sanmiguel, y que codirigió hasta 1960. Con base en un examen del catálogo de la editorial para este periodo y desde un enfoque que enlaza los intereses de la historia del libro con la sociología de la literatura, se plantea que Guadarrama fue usada por el escritor como una plataforma para ganar reconocimiento dentro de la escena literaria española y para orquestar la visibilidad internacional de su obra y la de otros autores colombianos amigos o próximos a las corrientes del hispanismo.

Palabras clave: Eduardo Caballero Calderón, Ediciones Guadarrama, literatura colombiana, industria editorial española, visibilidad literaria.

\section{EDUARDO CABALLERO CALDERÓN AND EDICIONES GUADARRAMA: PUBLISHING AND LITERARY VISIBILITY BETWEEN COLOMBIA AND SPAIN, 1954-1960}

This article studies the publishing activity of the Colombian writer Eduardo Caballero Calderón in Guadarrama Ediciones, the publishing house he founded in Madrid in 1954 together with

1 Este artículo es uno de los resultados del proyecto de investigación "La edición Ex Patria. Hacia una historia de las experiencias editoriales de colombianos en el extranjero", financiado por el Instituto Caro y Cuervo. 
the Spanish publisher Manuel Sanmiguel and co-directed until 1960. Based on a reconstruction of the Guadarrama catalog between 1954 and 1960, and through an analysis that links the history of the book with the sociology of literature, it is argued that Guadarrama was used by Caballero Calderón as a platform to gain recognition within the Spanish literary scene, as well as to orchestrate the international visibility of his literary work and that of other Colombian authors who were friends or close to his Hispanist thought.

KEYWORDS: Eduardo Caballero Calderón, Ediciones Guadarrama, Colombian literature, Spanish publishing industry, literary visibility.

Recepción: 01/04/2020

Aprobación: 14/11/2020

\section{INTRODUCCIÓN}

Antes del boom literario latinoamericano, la presencia y valoración de la literatura colombiana en el mercado del libro europeo era precaria. A pesar de que varios autores lograron publicar en Francia y España desde finales del siglo XIX, la mayor parte de estas obras no se planteaban irrumpir entre los lectores europeos, siendo su destino comercial natural los países de origen de sus autores ${ }^{2}$. Practicado con especial rigor por las casas parisinas desde mediados del siglo XIX, este modelo de negocio se mantuvo, con algunas excepciones, hasta la década de 1940, remarcando la ausencia en América Latina de empresas editoriales sólidas, que garantizaran a los autores locales seguridad económica o, por lo menos, un prestigio del cual disfrutar. Publicar en las principales capitales europeas brindaba, en consecuencia, una cuota de excepcionalidad.

Sin embargo, los cimientos de este patrón no serían siempre estables. El boom literario fue el fenómeno que los desajustó con mayor fuerza, pues potenció, como nunca, que la literatura del continente fuera consumida de forma regular entre los lectores europeos ${ }^{3}$. La concentración de los investigadores sobre este gran episodio ha evitado, no obstante, que casos previos de edición de autores latinoamericanos en Europa sean identificados

2 Entre la bibliografía disponible sobre el lugar de Francia y España en el mercado del libro hispanoamericano, véanse especialmente los trabajos de Pura Fernández (174-187) y Ana Martínez Rus (1033-1058).

Sobre la trascendencia del fenómeno en términos intelectuales y editoriales, los análisis de Nora Catelli (712-717) y Fabio Espósito (1-10) resultan ineludibles. 
$\mathrm{y}$, por tanto, atendidos con suficiencia ${ }^{4}$. Antes del boom, las estancias europeas de los escritores solían facilitar un acercamiento especial al oficio editorial, y no porque este fuese ajeno para figuras que pudieron haberlo ejercido en sus ciudades de origen, sino porque lo realizaban en un espacio que, con todas las restricciones financieras que podía acarrear, brindaba a la vez toda una paleta de ventajas simbólicas: visibilidad, reconocimiento, posicionamiento.

En relación con este fenómeno, este artículo reconstruye la inmersión en el mundo editorial español del escritor colombiano Eduardo Caballero Calderón (1910-1993), cofundador y director de Ediciones Guadarrama entre 1954 y 1957. La hipótesis que recorre este trabajo es que el escritor, consciente de provenir de un "espacio desposeído" - por parafrasear a Pascale Casanova (148-150)-, hizo de Guadarrama la punta de lanza de su obra en España y un medio de difusión de autores colombianos en el extranjero. Fundada en compañía de Manuel Sanmiguel (1913-1988), un sacerdote secularizado y exdirector de la editorial Afrodisio Aguado, la editorial debutaría con la intención "de dar a conocer en América libros españoles y de presentar en España lo más florido de la literatura suramericana" ("Caballero Calderón, novelista del llano" 19), objetivo que resultaría, empero, acotado a la presencia colombiana en su catálogo y al empuje de la figura del escritor en la escena literaria española.

Las páginas siguientes interrogan este proyecto a las luces de la historia del libro y de la sociología de la literatura. Ocurrido en el marco de la dictadura franquista, pero también en los albores del boom, el caso de Guadarrama resulta ejemplar para analizar las estrategias de un escritor latinoamericano para abrirse caminos de reconocimiento distintos a los que propiciarían más tarde la integración de América Latina a la república mundial de las letras, así como para avanzar en un análisis más interconectado de la experiencia editorial hispanoamericana, no sujeto a los límites y cargas de lo nacional (Lyons y Mollier 19).

Partiendo con una mirada al itinerario de Caballero Calderón antes de la creación de la empresa, el artículo avanza en una reconstrucción del catálogo

\footnotetext{
Pablo Neruda cultivó, por ejemplo, buena parte de su reconocimiento durante su segunda estancia en Madrid, en la cual conectó con círculos literarios que favorecieron su colaboración en revistas y alentaron la reedición de su trabajo Residencia en la tierra en 1935. Durante este mismo periodo, y replicando experiencias como las de Rubén Darío, el poeta pudo además concebir el proyecto revisteril Caballo verde para la poesía, que alcanzó cinco números ante de estallar la Guerra Civil en 1936 (Panero 58-59).
} 
de Guadarrama en su dimensión colombiana y analiza la materialidad de sus libros como un elemento que, pensado en términos de una poética de los soportes, llevó las obras de los escritores colombianos a otro nivel de atención ${ }^{5}$. Finalmente, y sosteniendo que la relación entre el escritor y la editorial fue provechosa para ambas partes, se concluye con un examen de sus trayectorias separadas después de 1960.

\section{ANTES DE ESPAÑA}

El itinerario intelectual de Eduardo Caballero Calderón está por reconstruirse. Aunque contamos con parte de sus memorias, estudios literarios y bibliográficos, y hasta con un trabajo biográfico realizado por su hija Beatriz -Papá y yo (2012)-, es todavía poco lo que sabemos sobre sus viajes latinoamericanos, su inserción en redes intelectuales o sus ideas frente a la edición, un elemento que asoma en los manuscritos de sus obras y que permitirían explorar su imaginación editorial ${ }^{6}$. Con todo, los estudios existentes permiten acercarse a su momento editorial de la década de 1950, aunque menos por lo que informan de sus operaciones intelectuales que por lo que advierten sobre su formación, amistades e intereses, siempre vitales para explorar su entendimiento e incursión en el mundo editorial.

En lo fundamental, Caballero Calderón puede considerarse un típico representante de la élite intelectual colombiana del siglo XX, una élite caracterizada por su cercanía al poder y casi natural desempeño en el periodismo militante. Hijo de un político y empresario liberal, y egresado del Gimnasio Moderno de Bogotá, el escritor creció en un ambiente circundado por el debate público y la cuestión mediática ${ }^{7}$. Su primera experiencia periodística

En torno a la noción de poética de los soportes nos sustentamos, por supuesto, en la obra de Thérenty (109-115). Conviene señalar que esta guarda lazos con el concepto de "enunciación editorial", el cual expone que, en cada libro o publicación, subyace un segundo texto cuyo significante no está formado por las palabras sino por la materialidad del medio (Souchier 140-145).

Estos manuscritos se encuentran encuadernados e integran la biblioteca personal de Eduardo Caballero Calderón, resguardada por su hija Beatriz Caballero Holguín, a quien se agradece la posibilidad de ojearlos.

Sobre la vida política y empresarial de Lucas Caballero Barrera (1869-1942), padre de Caballero Calderón, la investigación de Pierre Raymond ofrece quizás la investigación más detallada. 
la tendría, de hecho, al interior de su propio colegio, donde fundó la revista El Aguilucho en 1927. En este mismo año se estrenaría también como columnista en El Espectador, experiencia que marcaría el inicio de una de sus actividades más estables.

Estos precoces pasos tenían, sin embargo, poco de extraordinario. Antes bien, representaban un ejercicio común para los miembros de las élites bogotanas, acostumbrados desde jóvenes a recorrer oficinas estatales y establecimientos periodísticos. Luego de estudiar Derecho en el Externado de Colombia, en el marco de la República Liberal (1930-1946), Caballero Calderón pasaría a ejercer sus primeros cargos públicos en la Asamblea de Boyacá y en el Departamento de Información y Prensa del Ministerio de Relaciones Exteriores, lugar donde comenzaría a ganar experiencia en diplomacia. El contexto le brindaba, pues, las condiciones ideales para iniciar una carrera política.

No obstante, desde mediados de la década de 1930, la actividad literaria y periodística empezó a desajustar lo que parecía ser una carrera promisoria. Fue este el periodo donde su colaboración en la prensa se hizo constante y donde también aparecieron sus primeros libros: Caminos subterráneos: ensayo de interpretación del paisaje (1936) y Tipacoque, estampas de provincia (1941). Los viajes también empezarían a alterar la vida del todavía joven escritor. En 1937 inició un viaje que le llevó por Brasil y Chile, y que tuvo una primera gran parada en Lima entre 1939 y 1941, donde trabajó como secretario de la Embajada de Colombia. Sobre 1941, y con el fin de acompañar a su padre en la Embajada de Colombia en Argentina, pasó a vivir en Buenos Aires con su esposa Isabel Holguín ${ }^{8}$. El fallecimiento de su padre impuso, sin embargo, un pronto retorno a Bogotá y al trabajo en El Tiempo, donde venía ejerciendo como corresponsal ${ }^{9}$.

Fue en esta nueva etapa nacional que su carrera como escritor despegaría, catalizada por su premiación en un concurso literario internacional y un notable nombramiento académico ${ }^{10}$. Para ser claros, este momento vería no

\footnotetext{
En Buenos Aires lograría publicar una nueva edición de Tipacoque con la editorial Inter-Americana.

Entre 1938 y 1940, el escritor publica más de 150 artículos en El Tiempo, y después, como corresponsal internacional, varias series de artículos resultantes de sus viajes (Bedoya y Escobar 158-170).

10 Algunas tareas políticas también se hicieron presente durante este momento, pues en 1943 Caballero Calderón fue diputado por Cundinamarca y un año después intervino en la
} 
solo la publicación de varios de sus ensayos de mayor recordación, como Suramérica, tierra del hombre (1942), Latinoamérica un mundo por hacer (1944) y El nuevo Príncipe: ensayo sobre las malas pasiones (1945), sino también su posicionamiento como una figura preciada en el mundo intelectual colombiano, gracias a la obtención de una mención honorífica en el segundo concurso de literatura de la Unión Panamericana y la editorial neoyorkina Farrar \& Rinehart (1943), y a su nombramiento como miembro de la Academia Colombiana de la Lengua (1944).

Como es evidente, el concurso jugó como una palanca de internacionalización, una vez que se trataba de una iniciativa que, impulsada desde Washington, tenía una escala continental y basaba su poder de atracción en el compromiso de traducir y publicar las obras ganadoras en los Estados Unidos ${ }^{11}$. Previo al ascenso del sistema contemporáneo de premios literarios y parte de una estrategia mayor de diplomacia cultural estadounidense hacia la región, este concurso se sostuvo en una extensa red de instituciones y revistas que se encargaban de su promoción y desarrollo. En Colombia, la Biblioteca Nacional recogió las propuestas, mientras que la Revista de las Indias funcionó como órgano de control, una vez que su jefe de redacción, el poeta e hispanista Eduardo Carranza, fungió como jurado nacional. Al igual que sus pares en otros países, Carranza debía seleccionar las mejores propuestas y conducirlas hacia el jurado internacional, una triada compuesta por Blair Niles, John Dos Passos y Ernesto Montenegro (Carrillo Reveles 292).

Si bien la faceta editorial del premio constituía su principal atractivo, en términos de visibilidad el andar del concurso garantizaba ya una amplia publicitación, gracias a su estructura revisteril y continental. Este factor cobraría especial valor para la segunda edición del certamen, pues como lo constata Carrillo Reveles, esta fue lanzada en un contexto atravesado por la incursión estadounidense en la Segunda Guerra Mundial y la consecuente baja en el empuje de los auspiciantes (308-311). En esta versión, sería la promoción por parte de las revistas la que mantendría vivo el interés por el

fundación de la Alianza Nacional Revolucionaria en compañía de Eduardo Carranza y Rafael Guizado.

11 Sobre la multiplicación de los premios literarios en la segunda mitad del siglo XX y sus repercusiones en la valoración de lo literario y el ejercicio editorial, el trabajo de James English resulta revelador (50-68). 
concurso de parte de escritores como Caballero Calderón, quien se convertiría en uno de los premiados.

Fue su ensayo Suramérica, tierra del hombre el galardonado con la mención de honor del concurso, y pese a tratarse de una obra ya publicada, la noticia recorrió el continente e impactó con fuerza en la escena literaria colombiana, virgen hasta entonces en materia de premios internacionales ${ }^{12}$. Como una de las publicaciones asociadas al certamen, la Revista de las Indias fue la primera en celebrar la mención ${ }^{13}$. En una nota titulada "El premio a Swann", sus redactores afirmaron que el logro debía servir a Caballero Calderón como una puerta para "extender su influencia intelectual y mostrarse ante un público más cuantioso y comprensivo de todas las posibilidades de su gran talento" (161). Dirigida por Germán Arciniegas y dueña de un radio de circulación continental, el eco dado por esta revista al concurso y su ganador proyectaría indudablemente la imagen del escritor como un nuevo valor de las letras colombianas ${ }^{14}$.

Meses después de este hecho, un segundo logro repercutió sobre la imagen de Caballero Calderón: su nombramiento como miembro de número de la Academia Colombiana de la Lengua (ACL), decisión tomada en septiembre de 1943 y verificada en ceremonia el 23 de abril de 1944. Junto con convertirlo en el escritor más joven en pasar a integrar el círculo letrado de mayor tradición en el país, este paso determinó que su figura empezara a proyectarse más allá de los pasillos americanos, una vez le engranaba dentro de las corrientes del hispanismo transnacional. Bien reconocido por su hispanofilia, Caballero Calderón fue presentado en la ceremonia como un "paladín del hispanismo" y un "tradicionalista" preocupado por el futuro de la lengua, la obra de Cervantes, los autores del Siglo de Oro y los escritores de la generación del 98 (Gómez Restrepo 9) ${ }^{15}$.

12 La obra ganadora en la categoría fue Peregrinaje de la hondureña Argentina Díaz Lozano, obra que fue traducida al inglés en 1944 ("Latin American literary contest prizewinners" 416-417).

13 Al momento del premio, Caballero Calderón había publicado ocho artículos en esta revista (Bedoya y Escobar 155-156).

14 La Revista de las Indias era financiada por el Ministerio de Educación de Colombia, pero se presentaba como órgano de la "Asociación de Escritores Americanos y Españoles", fundada en 1938.

15 En relativa contradicción con el hispanismo del escritor, cabe subrayar también su faceta afrancesada, evidente en su seudónimo periodístico "Swann”, inspirado en Marcel 
Impulsado por este nombramiento, el "hispánico periplo" de Caballero Calderón, como lo denomina Gutiérrez Girardot (132), continuaría en lo sucesivo. Su convencimiento de que España constituía un renovado meridiano intelectual para las letras latinoamericanas quedó plasmado en su obra posterior, sobre todo a partir de su primer viaje entre finales de 1946 y mediados de 1948, momento en que fundó las relaciones que desembocaron, una década después, en Ediciones Guadarrama. Al igual que otros de sus viajes internacionales, este se adelantó gracias a su nombramiento como encargado de negocios, y si bien desconocemos qué tan consciente era el escritor de la posibilidad de obtener este cargo, las condiciones para su posible incursión en España ya habían empezado a sembrarse.

En abril de 1945, la Revista de las Indias publicó el capítulo final de una obra que el escritor venía preparando con el título Breviario del Quijote. Publicado en vísperas del cuarto centenario del natalicio de Cervantes, este adelanto debió llamar la atención de los círculos cervantinos españoles, que, atentos al comienzo y desarrollo de su cargo consular, impulsaron su nombramiento como miembro de la Real Academia de la Lengua en 1947 y le invitaron a participar de la II Asamblea Cervantina del mismo año. En paralelo, su anunciado Breviario del Quijote fue lanzado en Madrid por la Editorial Afrodisio Aguado, casa entonces dirigida por Manuel Sanmiguel, futuro amigo y socio.

La buena relación que se estableció entre ambos determinó que un nuevo libro fuese publicado después por la misma editorial: Cervantes en Colombia (1948), compilación que reafirmó el nombre de Caballero Calderón entre las huestes hispanistas ${ }^{16}$. La significancia de estos logros no pudo detener, sin embargo, el término de sus funciones consulares en España, una vez que la trágica situación que atravesó Colombia por el asesinato del líder liberal Jorge Eliécer Gaitán impuso su retorno en 1948.

Proust, y patente por igual en su trabajo como traductor de Paul Claudel, John Brown y el mismo Proust.

16 Financiada por el Patronato del IV Centenario de Cervantes, esta obra incluyó la ponencia "Contribución de la crítica colombiana al estudio de Cervantes", presentada por Caballero Calderón en la referida Asamblea Cervantina, y una larga serie de artículos sobre Cervantes escritos por autores colombianos como Rufino J. Cuervo, Miguel Antonio Caro, Baldomero Sanín Cano y Darío Achury Valenzuela. 


\section{GUADARRAMA EDICIONES: PRIMERA Y COLOMBIANA ÉPOCA}

Fue en la segunda estancia española del escritor, entre 1952 y 1957, que Ediciones Guadarrama vería la luz, pero la deuda de este proyecto con su primera experiencia sería evidente. Por el lado creativo, esta le había representado aprendizajes y abierto a nuevos temas, mientras que por el de las relaciones favoreció su acercamiento a círculos literarios y a la industria editorial local. La primera estancia sería igualmente fructífera en términos de visibilidad, pues Caballero Calderón pasó en este periodo de tener una exposición meramente nacional a tener una mucho mejor situada, académica e hispanista por los espacios que pudo aprovechar, pero también internacional y europea, a pesar de la situación de España. Tal como ocurrió con el concurso literario latinoamericano, la primera experiencia madrileña supuso un paso clave en la elevación de su "capital de visibilidad". Definido por Nathalie Heinich como aquel recurso que marca diferencias o asimetrías entre las personas que son conocidas y las que no lo son, el capital de visibilidad puede conferir a sus detentores prestigio, poder, relaciones y dinero. Aunque se emparenta con las demás declinaciones del término propuestas por Bourdieu, este capital se articula con mayor fuerza al régimen mediático contemporáneo y no resulta reducible a ninguna otra forma de capital, ni siquiera al social, pues, como explicita Heinich, este simplemente mide el alcance y la calidad del conocimiento o las relaciones, mas no el grado de reciprocidad (43-47) ${ }^{17}$.

Vertido al caso de los escritores, el capital de visibilidad puede connotar, empero, un carácter negativo, una vez que el exceso de exposición puede contraponerse con el valor literario, y más aún en las actuales condiciones de la comunicación global, donde la tendencia a la sobrexposición puede extremarse. Con todo, para el caso de los escritores colombianos de mediados del siglo XX, un periodo donde la televisión distaba de generalizarse y el problema de la publicidad se restringía a medios impresos y radiales, el interés en la visibilidad era palpable. Como lo entendían los redactores de la Revista de las Indias, los premios daban la posibilidad de alcanzar una posición continental, pues modificaban el estatus de sus ganadores y podían lanzarles allende las fronteras nacionales.

17 Para Heinich, vale resaltar, el capital de visibilidad es un recurso medible, acumulable, transmisible, que genera intereses y puede convertirse (47). 
La experiencia de Caballero Calderón luego de su primer viaje a España o incluso después de la mención recibida en el concurso de la Unión Panamericana es diciente del incremento de su visibilidad. Basten dos ejemplos para ilustrarlo. En diciembre de 1943, una columna del intelectual español José Prat, exiliado por entonces en Bogotá, informaba que Caballero Calderón había sido reclutado por Arturo Soria, otro español exiliado en Chile, para dirigir una "Colección de autores colombianos" en la Editorial Cruz del Sur (1). Aunque la colección no lograría formarse, la noticia ubicaba al escritor colombiano en horizontes de reconocimiento que tocaban la edición chilena y las redes del exilio español en América.

El segundo ejemplo enlaza con el éxito de la novela El cristo de espaldas (1952), que convirtió a Caballero Calderón en protagonista de una nueva revista bogotana: Índice cultural. Creada por los poetas Óscar Delgado, Fernando Charry Lara y Aurelio Arturo, esta debutó en junio de 1952 dedicando buena parte de su sección bibliográfica a republicar las reseñas hechas a esta novela, que alcanzó el estatus de best seller en Colombia, con alrededor de 6.000 ejemplares vendidos, y provocó controversia debido a que avanzaba sobre el tema de la violencia colombiana y el papel jugado en ella por miembros la Iglesia ("Libros de Ahora", Índice 1 22-23). La importancia del suceso llevó a que el segundo número de la revista se dedicara especialmente al escritor, usando su fotografía de portada y abriéndole un espacio para una "autocrítica". Allí, Caballero Calderón se excusó por la premura con que concluyó la novela -debido, según expuso, a las presiones de la editorial Losada-, pero obvió las acusaciones de anticlericalismo y sectarismo que había recibido. Claramente de su lado, los responsables de Índice acompañaron este especial con nuevas y positivas críticas hacia la novela ("Libros de Ahora", Índice 2 50-51) ${ }^{18}$.

Estando ad portas de su segundo viaje a España en 1952, el escritor colombiano podía considerarse una figura no solo reputada en el medio literario en su país, sino también una bien situada en la república latinoamericana de las letras. Sus obras despertaban la curiosidad de críticos y lectores, y le permitían capturar la atención de transnacionales de la edición como Cruz

18 Cabe decir que muchas de las opiniones desfavorables buscaron contestar el juicio emitido por Hernando Téllez, el más respetado crítico del país, quien manifestó que El cristo de espaldas era la mejor novela colombiana que había leído. 
del Sur y Losada ${ }^{19}$. Los pasos siguientes de Caballero Calderón mostrarían, no obstante, que la ventana suramericana le era insuficiente. Si algo parecía interesarle desde su primer viaje a España era el ser apreciado en ese entorno cultural que le atraía de sobremanera. "No tuve la impresión de llegar, sino la de volver", escribió emocionado en Ancha es Castilla a propósito de su entrada terrestre desde Portugal a España (9). La creación de Ediciones Guadarrama puede verse entonces como la fórmula concebida por el escritor para atraer nuevas miradas españolas hacia su obra.

Si bien las fuentes necesarias para explorar al detalle los orígenes de este proyecto no abundan, los archivos del Instituto Nacional del Libro Español (INLE), resguardados en el Archivo General de la Administración (AGA), permiten reconstruir sus inicios legales. Según el expediente de Ediciones Guadarrama, ubicado en el fondo Registro de Empresas Editoriales (REE), esta se formó el 22 de noviembre de 1955 con un capital de $\$ 750.000$ pesetas, suma aportada por tres socios: Manuel Sanmiguel Raimúndez, Eduardo Caballero Calderón y Domingo Ezquerra Plata. La documentación señala que esta sociedad se mantuvo intacta hasta febrero de 1960, momento en que Sanmiguel y una nueva socia, Pilar Vega García, adquirieron el total de las acciones (AGA, INLE, REE, Caja 62/6441 expediente 8) ${ }^{20}$.

La participación de Caballero Calderón abarcó así, y al menos en la formalidad notarial, poco más de cuatro años. En cuanto al objetivo de la editorial, plasmado también en la documentación del REE, se expone que este consistía en "la publicación de obras culturales a un nivel universitario: filosofía, arte, sociología, historia y ensayos críticos” (ibid.). Para desarrollar sus planes, explicitaba un registro mercantil, contaba con el capital social y las ventas de su fondo "sobre todo en América, a donde exporta, más o menos, el 60\% de su producción” (ibid.).

19 La relación que estableció con Losada sería, de hecho, elocuente de su nueva posición, pues, con motivo de la apertura de una sede de la editorial en Bogotá, a fines de 1951, Caballero Calderón fue elegido para dar el discurso de bienvenida, momento en que la definió como una ventana para que los lectores colombianos mirasen más allá de las fronteras y los escritores del país pudiesen también ser mirados desde afuera (Caballero Calderón, Ventana sobre América 3).

$20 \quad$ En el libro Historia de la edición en España 1939-1975, Martínez Martín presenta estos datos con algunas imprecisiones, pues señala a Sanmiguel y Vega como socios fundadores en 1955, momento en el que la segunda todavía no figuraba en la sociedad. Asimismo, el autor indica que el capital inicial fue de $\$ 2.250 .000$ pesetas, cuando esta cifra fue, en realidad, resultado de un aumento del capital de la empresa ocurrido en marzo de 1964 (334). 
En un documento adicional, firmado el 29 de noviembre de 1968, y cuyo membrete refiere también al "Registro de Empresas Editoriales ante el Ministerio de Información y Turismo" (ibid.), Sanmiguel insiste sobre el carácter académico de la empresa. En sus palabras, Guadarrama tenía propósitos eminentemente culturales, o sea, "que todos los libros que publica se dirigen a núcleos universitarios, o de un nivel de cultura superior". En seguida, especificaba que la editorial se movía en el marco de las llamadas "ciencias del espíritu" y que, en probable respuesta a las interrogantes de la burocracia censora, no eran de su interés las obras técnicas, ni los libros infantiles o juveniles, ni tampoco "los que se refieren a la política o a la actualidad" (ibid.).

Aunque fechada en la década de 1960, esta información concuerda con la suministrada por Sanmiguel en una entrevista publicada en la revista El libro español en 1958, momento en que Caballero Calderón todavía era su socio. En esta, el editor acentúa menos el carácter académico de Guadarrama que su horizonte doble: europeísta e hispanoamericano. Según señala, la editorial había surgido con el fin de "publicar en España las obras de las figuras de Hispanoamérica, y de dar a conocer a nuestros escritores jóvenes en aquellas tierras", pero se interesaba también por los problemas de la cultura europea. Consultado por las dificultades que acarreaba tener la mira en América, Sanmiguel respondió que toda editorial española debía estar volcada hacia esa región, pues el libro español gozaba allí "de gran prestigio y confianza" y "el afán de cualquier literato hispanoamericano" era publicar en Madrid o Barcelona (Sanmiguel 331-333).

Explicado por la presencia de Caballero Calderón en la compañía, este objetivo marcó el discurso de la editorial, pero no representó por completo su realidad práctica. Si bien fueron muchas las novedades españolas que circularon hacia América, aquellas que buscaron ganar lectores españoles fueron casi todas colombianas. De un total de 59 títulos publicados por Guadarrama antes de 1960, un total de 19 (32\%) fueron de autores o temas colombianos, de entre los cuales seis fueron del propio Caballero Calderón ${ }^{21}$. De entre estos, sin embargo, solo la mitad fueron novedades: La penúltima hora (1955), Americanos y europeos (1957) y el libro turístico El Valle del Cauca (1956), primer y único volumen de una frustrada colección denominada

21 Esta cuenta es solo aproximada del número de títulos publicados por Guadarrama durante el periodo. 
"Por Tierras de Colombia". El resto fueron reediciones de algunos títulos importantes, como Ancha es Castilla (1954), Suramérica, tierra del hombre (1956) y la novela Siervo sin tierra (1955), que ya contaba entonces con una primera edición española publicada bajo el sello de Ediciones del Alcázar ${ }^{22}$.

\section{Tabla 1.}

Libros de autores y/o títulos colombianos publicados por Guadarrama

\begin{tabular}{|c|c|c|c|c|}
\hline Año & Autor & Título & Presentación & Págs. \\
\hline 1954 & E. Caballero Calderón & Ancha es Castilla & --- & 336 \\
\hline 1954 & Andrés Holguín & $\begin{array}{l}\text { Poesía francesa. } \\
\text { Antología }\end{array}$ & --- & 700 \\
\hline 1954 & Tomás Rueda Vargas & La sabana y Bogotá & $\begin{array}{l}\text { E. Caballero } \\
\text { Calderón }\end{array}$ & 302 \\
\hline 1954 & José Asunción Silva & $\begin{array}{l}\text { El libro de versos y } \\
\text { otras poesías }\end{array}$ & $\begin{array}{l}\text { E d u a r d o } \\
\text { Carranza }\end{array}$ & 158 \\
\hline 1955 & Juan Pablo Varela & $\begin{array}{l}\text { Cuentos en verde } \\
\text { pálido }\end{array}$ & --- & 130 \\
\hline 1955 & E. Caballero Calderón & $\begin{array}{l}\text { La penúltima hora. } \\
\text { Novela }\end{array}$ & --- & 215 \\
\hline 1955 & E. Caballero Calderón & Siervo sin tierra & --- & 250 \\
\hline 1955 & Rafael Pombo & Cuentos pintados & $\begin{array}{l}\text { E. Caballero } \\
\text { Calderón }\end{array}$ & 98 \\
\hline 1955 & Herbert Boy Dupuis & Una historia con Alas & $\begin{array}{l}\text { E. Caballero } \\
\text { Calderón }\end{array}$ & 277 \\
\hline
\end{tabular}

22

Aunque carecemos de fuentes que lo confirmen, Ediciones del Alcázar parece haber sido el proyecto editorial piloto del cual resultaría Guadarrama, pues la edición de Siervo sin tierra, de 1954, es exacta en su formato y presentación a la realizada después bajo Guadarrama. 


\begin{tabular}{|c|c|c|c|c|}
\hline 1955 & Rafael Arango Villegas & Obras completas & $\begin{array}{l}\text { E. Caballero } \\
\text { Calderón }\end{array}$ & 697 \\
\hline 1956 & E. Caballero Calderón & El Valle del Cauca & $\begin{array}{l}\text { Luis Martínez } \\
\text { Delgado }\end{array}$ & 71 \\
\hline 1956 & E. Caballero Calderón & $\begin{array}{l}\text { Suramérica, tierra } \\
\text { del hombre }\end{array}$ & --- & 312 \\
\hline 1956 & $\begin{array}{l}\text { Mariano Izquierdo } \\
\text { Gallo C.M.F. }\end{array}$ & $\begin{array}{l}\text { Mitología americana. } \\
\text { Selección de los mitos } \\
\text { aborígenes }\end{array}$ & --- & 479 \\
\hline 1956 & $\begin{array}{l}\text { Guillermo Torres } \\
\text { García }\end{array}$ & $\begin{array}{l}\text { Miguel Antonio } \\
\text { Caro, su personalidad } \\
\text { politica }\end{array}$ & --- & 264 \\
\hline 1957 & E. Caballero Calderón & $\begin{array}{l}\text { Americanos } y \\
\text { europeos }\end{array}$ & --- & 376 \\
\hline 1957 & Tomás Rueda Vargas & Deciamos ayer & Los editores & 234 \\
\hline 1957 & Luis Galvis Madero & El adelantado & $\begin{array}{r}\mathrm{C} \text { a } \mathrm{r} \text { l } 10 \mathrm{o} \\
\text { Restrepo Canal }\end{array}$ & 386 \\
\hline 1958 & María Teresa Mejía & $\begin{array}{l}\text { Demasiado tarde. } \\
\text { Novela }\end{array}$ & $\begin{array}{l}\text { E d u a r d o } \\
\text { Santos }\end{array}$ & 179 \\
\hline 1958 & Arcadio Dulcey & Una mujer perdida & --- & 224 \\
\hline 1958 & Germán Pardo García & Poemas & $\begin{array}{ll}-- \\
---\end{array}$ & 109 \\
\hline
\end{tabular}

Fuente: Esta tabla se basa en la revisión de los libros en diferentes locaciones, como la Biblioteca José Manuel Rivas Sacconi del Instituto Caro y Cuervo, la Biblioteca Nacional de Colombia, la Biblioteca Nacional de España, y la Biblioteca personal de Eduardo Caballero Calderón. 
Como se aprecia en la Tabla 1, la presencia colombiana fue abiertamente mediada por Caballero Calderón, quien escribió los prólogos para los libros de Tomás Rueda Vargas, Arango Villegas y Rafael Pombo. El ahora editor presentó asimismo el libro sobre El Valle del Cauca e intervino en el del piloto alemán Herbert Boy (1955), residente en Colombia, el cual se subtituló como una obra "con la colaboración y un punto final de E. Caballero Calderón". De acuerdo con Pierre Bourdieu, estas operaciones de "marcación" resultan necesarias para introducir autores desconocidos en nuevos campos de recepción y representan actos típicos de transferencia de capital simbólico (3-8), provenientes para este caso de un escritor que, pese a su condición de autor extranjero, era ya por entonces un miembro de la RAE y tenía incluso en su haber un libro que le había hecho ganar fama de hispanista militante: Ancha es Castilla, del cual hasta el mismísimo duque de Alba habría afirmado que era "uno de los libros más bellos y penetrantes escritos sobre España" ("Caballero Calderón, novelista del llano" 19) ${ }^{23}$.

Vale señalar que estas tareas de mediación jugaban como un ejercicio de autopromoción adicional para Caballero Calderón, quien añadía así a su reputación de escritor las capacidades de selección del editor. En cuanto a la escena colombiana, se trataba también de una tarea que lo posicionaba como un actor clave en la internacionalización de la literatura de su país o, por lo menos, de aquella de la que se sentía más deudor. Con todo, no parece haber existido un criterio claro en la escogencia de los títulos colombianos que integraron el catálogo o, al menos, no uno basado en términos de autoridad literaria. De entre los seleccionados, solo José Asunción Silva y Rafael Pombo podían considerarse parte del todavía impreciso canon literario colombiano. En notable contraste, los nombres de Juan Pablo Varela, María Teresa Mejía y Arcadio Dulcey eran casi desconocidos. En un punto medio estaban los poetas Germán Pardo García y Andrés Holguín, ambos bien apreciados localmente, y también Tomás Rueda Vargas, viejo maestro de Caballero Calderón en el Gimnasio Moderno de Bogotá. Arango Villegas contaba con cierto renombre como humorista, mientras que Torres García, Galvis Madero e Izquierdo Gallo, este último un padre español asentado en Colombia, eran

23 Un par de años atrás, una reseña publicada en el conservador periódico $A B C$ afirmó que Ancha es Castilla colocaba a su autor "en la primera fila de los biógrafos de un país" ("Libros y revistas" 43-44). 
tenidos por académicos reputados ${ }^{24}$. A estos tres los unificaba, empero, el marco hispanoamericano de sus obras.

La carencia de fuentes epistolares o contratos de edición impide, como es lógico, precisar las razones detrás de la selección de estas obras, pero es posible proponer que entre ellas puede haber estado la necesidad, por parte de Caballero Calderón, de dar otro sentido a títulos que, de haber aparecido en Colombia, habrían tenido una proyección y presentación editorial muy pobre. En efecto, si algo mostraban los libros de Guadarrama era una preocupación por su materialidad, factor que les diferenciaba ampliamente de los libros entonces publicados en las capitales colombianas. Impresos en formatos que oscilaban entre el octavo $(18 \mathrm{~cm})$ y el cuarto menor $(25 \mathrm{~cm})$, encuadernados en tela, con rótulos en dorado, arropados por sobrecubiertas fotográficas o "a todo color", y rebosantes en imágenes, los libros de Guadarrama exudaban elegancia. El mismo Sanmiguel, que se veía a sí mismo como un arquitecto del libro, mencionó este aspecto como una de las fortalezas de la editorial: "si el ánfora es bella, es más atractivo su contenido" (332).

En el caso del componente colombiano, esta característica relucía aún más. Así, por ejemplo, Ancha es Castilla se nutrió con 38 ilustraciones en huecograbado y Suramérica, tierra del hombre con 32, mientras que los Cuentos pintados de Pombo incluyeron 16 litografías a diez colores del reconocido ilustrador español Casajuana ${ }^{25}$. Títulos menores dentro del catálogo tuvieron también en las imágenes un recurso de excepción. Una historia con alas contó con 32 fotografías, mientras que las Obras de Arango Villegas se acompañaron de dibujos del caricaturista colombiano Alberto Arango Uribe (1887-1941). El caso de La sabana y Bogotá no fue distinto, pues incluyó 30 fotografías e incluso un retrato de su autor, siendo el único título del grupo con este apoyo. Junto con el formato acondicionado, este detalle elevó claramente la presentación de una obra cuya primera edición de 1919 había sido descrita como un devocionario (Nieto Caballero 44) ${ }^{26}$.

24 Debido a su condición sacerdotal, Izquierdo Gallo debió someter su manuscrito al Superior Provincial de Colombia, quien la aprobó el 30 de agosto de 1956, previa revisión del censor claretiano Francisco Martín.

25 Para el trabajo de las sobrecubiertas, se pudo establecer que Guadarrama contó con los servicios del fotógrafo húngaro Nicolás Müller y los ilustradores Serny y Antonio Mingote.

26 Cabe subrayar que la materialidad de Guadarrama resaltó en la misma España, pues, en diciembre de 1955, dos títulos de la editorial fueron seleccionados por los redactores 
Por fuera de la prodigalidad gráfica, la enmarcación de los libros al interior de colecciones sumó a su atractivo. Las series más amplias y destacadas de la editorial fueron "Panoramas" y "Crítica y ensayo", esta última formada por estudios de autores españoles como Domingo Pérez Minik, Luis F. Vivanco y Gonzalo Torrente Ballester, pero también por traducciones de Paul Hazard, Jean Cassou y Georges Duhamel ${ }^{27}$. Aunque no lograron la misma notoriedad, las colecciones propias al componente colombiano también destacaron por su sobriedad. Ancha es Castilla y Suramérica, tierra del hombre formaron así la colección intitulada "Del Pirineo a los Andes", mientras que la reedición de Siervo sin tierra se presentó como parte de la serie "Escritores colombianos -contemporáneos-", rótulo no identificado en otros títulos. La penúltima hora fue también el único libro de la colección "Los Libros del Sauce", al igual que El libro de versos y otras poesías de Silva, solitario ejemplar de la serie "Madrigal de las Altas Torres"28.

La preocupación por la forma de los libros pareció remarcar más que un interés estético. Si bien es claro que se trataba de un recurso que le permitía a la editorial irrumpir como un sello elegante y riguroso, parece claro que el interés de Caballero Calderón para con sus libros y los de sus amistades era el de brindarles un estándar editorial distinto, donde la imagen presuponía un nuevo valor. Tanto la localización madrileña como el respaldo de un experimentado editor como Sanmiguel proporcionaban al escritor las condiciones necesarias para alcanzar este cometido. Las elecciones técnicas exponen así una labor de mediación interesada en enriquecer los textos para adaptarlos a un espacio de recepción nuevo, pero al mismo tiempo para reposicionarlos en su geografía de origen bajo una nueva y más atractiva impronta, donde relucían los contenidos gráficos y las presentaciones copiosas en información

del periódico $A B C$ entre "Los libros mejor editados del año" ("Los libros" 47). Se trató de la antología Poesía francesa de Andrés Holguín y de las memorias Dentro y fuera de mi vida de Agustín de Figueroa, reconocimientos que, si bien menores, ayudaron a posicionar a la empresa dentro del mercado español.

$27 \quad$ Americanos y europeos hizo también parte de esta colección, al igual que la traducción de la compilación Hacia un nuevo humanismo (1957), realizada por el mismo Caballero Calderón.

28 La edición de este libro fue muy distintiva, pues sus títulos y letras capitales se imprimieron en tinta roja y el logotipo de la colección, cuyo nombre proviene de un pueblo de la provincia de Ávila, se estampó en dorado sobre una cuidada encuadernación en tela. Esta obra fue además ilustrada por Serny y prologada por Eduardo Carranza, por entonces secretario de la Embajada de Colombia en España. 
peritextual en páginas de guarda, colofones y sobrecubiertas, lugares donde la calidad del producto se hacía evidente.

Puesta en relación con el problema de la visibilidad, la enunciación editorial propuesta por Guadarrama sumó al prestigio del sello y al de sus responsables. En primer lugar, la empresa vio ganarse pronto un lugar dentro de los circuitos académicos. En una encuesta adelantada por el INLE en 1957, en la que se preguntaba a un amplio grupo de escritores por los mejores libros del año, títulos de Guadarrama como Retrato de Unamuno de Luis Granjel, Teatro español contemporáneo de Torrente Ballester y Panorama de las ideas contemporáneas de Gaëtan Picón fueron mencionados (Instituto Nacional del Libro Español, 16-18, 30 ${ }^{29}$. Sumado a su constante presencia en la Feria del Libro desde 1957, es fácil suponer que la marca fue pronto recordada dentro del mercado español. En segundo lugar, es posible plantear que las elecciones editoriales se tradujeron en nuevas consideraciones hacia la figura de Caballero Calderón y del mismo Sanmiguel. En general, la presencia del colombiano en medios y espacios de sociabilidad se fue ampliando hasta 1957, año de su retorno a Colombia, siendo rastreable en entrevistas concedidas a la revista $L a$ Hora y en reseñas de sus libros publicadas en el periódico $A B C$, medio donde los anuncios de Guadarrama juntaban a Caballero Calderón con Arnold Hauser y Karl Jaspers.

Conviene destacar que esta dinámica publicitaria también se manifestó en Colombia, de la mano del mismo Caballero Calderón. Gracias a la continuidad de sus colaboraciones con El Tiempo, las páginas culturales del periódico hicieron eco de los títulos colombianos publicados por Guadarrama desde 1955, publicando reseñas como la realizada a la antología Poesía francesa de Holguín, primer original colombiano de la editorial, así como al libro de Torres García dedicado a Miguel Antonio Caro. A finales de 1956, el prólogo a la nueva edición de La sabana y Bogotá de Rueda Vargas fue incluso republicado entero ${ }^{30}$.

29 Entre los escritores que destacaron estas obras se encontraban Luis Felipe Vivanco, Pedro de Lorenzo y Vicente Marrero, este último director de la revista Punta Europa.

$30 \quad$ Véanse al respecto las ediciones de El Tiempo. Suplemento literario del 30 de enero de 1955 (1); del 10 de abril de 1955 (3); y El Tiempo. Lecturas dominicales del 30 de diciembre de 1956 (8). En una entrevista otorgada a Índice cultural en 1957, Caballero Calderón indicó tener listas para su publicación con Guadarrama títulos de autores como León de Greiff, Gabriel Giraldo, Alfonso López, Joaquín Quijano Mantilla y hasta de su hermano Lucas Caballero Calderón, todos trabajos que no llegaron a publicarse. 
Si bien un análisis más sistemático sobre la presencia de Caballero Calderón en medios colombianos y latinoamericanos se hace necesario para medir el impacto real de la experiencia editorial en su visibilidad pública, su itinerario posterior confirma que su peso como figura autoral e intelectual era uno distinto luego de finalizar su segunda estancia española. Cada nueva obra que lanzaba era objeto de atención inmediata por parte de colegas periodistas y de la emergente crítica literaria colombiana, que no perdió la oportunidad de reseñar sus obras en distintos medios.

La labor de la crítica sería, de hecho, una de las más reveladoras de la nueva posición de Caballero Calderón en el medio intelectual nacional, y no porque fuese una admiradora acérrima. La recepción dada al ensayo Americanos y europeos brinda un buen ejemplo, pues a pesar de ser un trabajo bien comentado en revistas españolas como Estudios Americanos, fue duramente criticado por Índice cultural, vieja defensora del escritor. Más allá de los argumentos negativos, interesa relevar que el ensayo pasó a integrar una llamativa lista de fracasos literarios de 1957 propuesta por la misma revista, que llevó por título: "Desaciertos u obras fallidas de autores consagrados" ("La Bibliografía de 1957” s/p).

Por fuera de estas cuestiones, una vez que retornó a Colombia, la situación de Caballero Calderón siguió revelando un nuevo estado de reconocimiento. Así, por ejemplo, para inicios de 1959 sería escogido por el poeta y editor peruano Manuel Scorza para conducir, junto con Alberto Zalamea, la realización de los Festivales del Libro en Colombia y coordinar la colección asociada a estos: la "Biblioteca Básica de Cultura Colombiana". Parte de un proyecto de ambición trasnacional encabezado por Scorza, esta iniciativa colocó a Caballero Calderón al nivel de otros escritores latinoamericanos escogidos por el poeta peruano para desarrollar los festivales, como Juan Liscano, Alejo Carpentier, Jorge Icaza y Miguel Ángel Asturias. Poco antes de iniciar la década de 1960, periodo en el que el boom latinoamericano comenzaría su despegue, Caballero Calderón contaba pues con un estatus que trascendía de forma elocuente el espacio cultural colombiano.

Engranada al impacto general de su obra literaria, la experiencia ibérica de Caballero Calderón pareció reportarle, en síntesis, beneficios materiales y simbólicos que redundarían en un proceso particular de internacionalización de su figura, alejado de las corrientes previas e incluso de las que darían posteriormente forma al boom, caracterizadas por conectar ciudades como Barcelona, París y Buenos Aires y elevar la posición de nuevos centros político-intelectuales como Cuba. La trayectoria posterior de Guadarrama 
también muestra dinámicas propias de avance sobre el espacio cultural latinoamericano. Reforzada con la entrada de nuevos accionistas en la década de 1960, Guadarrama ganó nuevas posiciones en América sin descuidar el objetivo de cautivar lectores españoles.

\section{VISIBILIDAD Y RECONOCIMIENTO EN LOS ALBORES DEL BOOM}

Visto desde la superficie, el fin de la relación entre Caballero Calderón y Guadarrama no representó un retroceso en la visibilidad del escritor ni en el reconocimiento transatlántico de la editorial. En los albores del boom, ambos lograron disparar sus ambiciones y ampliar su estatus. Junto con asegurar la circulación de sus colecciones en la región, labor respaldada por las librerías hispanistas e instituciones como el INLE - que tuvo también entre sus tareas la coordinación de la presencia editorial española en las ferias del libro latinoamericanas ${ }^{31}$-, Ediciones Guadarrama se convirtió en la década de 1960 en editora de las series venezolanas "Biblioteca de la Academia Nacional de Historia" y "Biblioteca Popular Venezolana", ambas financiadas por el Ministerio de Educación de Venezuela.

A la par de estos nuevos lazos, Guadarrama logró ampliar su fondo hasta el fin de su itinerario en 1975, año en que fue adquirida por la Editorial Labor de Barcelona. Entre los nuevos proyectos se encontraron la serie "Historia y pensamiento", la "Biblioteca de ciencias humanas", la "Biblioteca para el hombre actual" y dos colecciones dirigidas en exclusiva a públicos estudiantiles: "Textos universitarios" y "Punto Omega. Colección universitaria de bolsillo", esta última una de las más recordadas ${ }^{32}$.

Paralela a esta evolución, la figura de Caballero Calderón continuaría en ascenso. Mientras su obra fue ampliándose con novelas como Manuel Pacho (1964) y Caín (1969), su visibilidad internacional se refrescaría con la obtención del Premio Nadal por El buen salvaje (1965), obra que fue presentada por la Editorial Destino como proveniente de un escritor hispanófilo influenciado por la generación del 98. En opinión de Burkhard

31 Sobre el origen y las funciones del INLE véase el minucioso análisis de Ana María Rodrigo (97-119).

32 Luego de vender la compañía, Sanmiguel se dedicaría a una nueva empresa, la Editorial Cristiandad, la que dirigió hasta su muerte en 1988. 
Pohl, esta presentación resaltaba la calidad literaria y lingüística de la obra al mismo tiempo que descontextualizaba el origen del autor para identificarlo casi como un español (184-185). Por supuesto, esta estrategia buscaba preciar los títulos latinoamericanos que empezaban a capturar el mercado ibérico, pero la misma pudo haber significado poco para alguien ya valorado dentro del medio. De todos modos, el premio reimpulsó la internacionalización del escritor y su obra, al favorecer la reedición de varios de sus libros e incrementar el interés por su novela Siervo sin tierra, la cual empezaría a traducirse en distintas lenguas europeas, como el italiano (1968), el francés (1969), el alemán (1970) y el checo (1976) ${ }^{33}$.

De este modo, y a diferencia de la mención recibida décadas antes en el concurso de la Unión Panamericana y la editorial Farrar \& Rinehart, la cual representó un estímulo limitado al continente americano, el Premio Nadal supuso la entrada definitiva del escritor colombiano al enredado espacio de producción de la literatura mundial, caracterizado por un paisaje de relaciones sociales y maniobras editoriales que buscaron definir, popularizar y mundializar, de forma sistemática, la literatura latinoamericana ${ }^{34}$.

En otras palabras, el contexto permitió a Caballero Calderón sumar su nombre y obra a la avanzada del boom, con todo y la distancia generacional y literaria que va a separarle de sus representantes. Como recuerda Gisèle Sapiro, los factores detrás de la circulación internacional de las obras literarias están incrustados, sin olvidar la prevalencia económica, en relaciones de poder entre grupos sociales (90-91). Al haber sufrido un proceso de internacionalización previo a la alineación de los factores que dieron origen al boom, proceso que implicó el cultivo de relaciones con editores, escritores y, en general, con un espacio editorial en reactivación como el español, el escritor lograría navegar bien en la nueva corriente, e incluso desde una posición privilegiada, una vez que su nombre contaba con recordación en dos espacios culturales distintos: en tanto escritor como editor.

Esta segunda cualidad incidió seguramente en su selección para el que sería el último de sus trabajos editoriales: la dirección de la colección

33 La traducción más temprana de esta obra sería, empero, realizada por la moscovita Pomah en 1963. También se realizó una edición en chino cuyo año desconocemos. Sobre el impacto de los premios en las políticas de traducción, Frank de Glas (169-177) aporta un estudio sustantivo alrededor del premio Formentor.

34 En torno a los mecanismos que implicaron la entrada de la literatura latinoamericana a la literatura mundial, las observaciones de Gustavo Guerrero et al. (1-13) resultan fundamentales. 
"Cimas de América", proyecto ideado por los responsables de la Revista de Occidente en $1967^{35}$. En esta nueva experiencia, el escritor no perdería la ocasión para funcionar como su propio intermediario, al reeditar uno de sus primeros ensayos, El nuevo príncipe, pero también para ejercer como un agente puente para otros escritores latinoamericanos, como Eduardo Mallea, Juan Carlos Onetti, Arturo Uslar Pietri, Germán Arciniegas, Mariano Picón Salas, Aurelio Miró Quesada y Enrique Anderson Imbert, quienes pasaron a integrar una de las colecciones más tempranas de literatura latinoamericana concebidas desde España.

\section{CONCLUSIONES}

De la misma manera que otros itinerarios intelectuales, el de Eduardo Caballero Calderón se caracterizó por su multiplicidad y movilidad. Como se pudo mostrar, su vida estuvo atravesada por la política, el periodismo y la literatura, pero igualmente por viajes, conexiones y ejercicios editoriales más o menos sostenidos en el tiempo. Lejos de ser desinteresadas, estas últimas facetas de su itinerario pueden leerse como parte de una estrategia de posicionamiento e internacionalización de su obra y figura en el plano de la literatura. Dicho de otro modo, la labor editorial en Caballero Calderón, ejercida en general desde una condición expatria y, por lo mismo, articulada con espacios y circuitos transnacionales, favoreció la proyección de su reconocimiento como escritor.

Como se ha tratado de mostrar, su papel en la creación y conducción de Ediciones Guadarrama ubicó su producción literaria y la de un círculo de amistades en un paisaje cultural que no solo le atraía particularmente, sino que le brindaba condiciones de posibilidad distintas en materia de acción editorial. A diferencia de la mayor parte de libros publicados en Colombia y América Latina, los concebidos por Guadarrama evidenciaron elecciones técnicas y estéticas que repercutían sobre los contenidos editados y que les aportaban un grado de distinción y pulcritud pocas veces visto en el espacio editorial latinoamericano, el cual, pese a su rápida modernización, para

35 Sobre esta época de la Revista de Occidente, véase el trabajo de Javier Escudero (185-196). 
mediados del siglo XX continuaba favoreciendo la producción de libros y colecciones menudas y económicas.

En adición al beneficio propiciado por el contexto, la labor editorial del escritor repercutió sobre la visibilidad de su obra, pues esta no solo pudo participar del mercado del libro español en mejores condiciones de presentación y publicitación, sino que lo hizo integrada a colecciones de ascendencia académica y ambición europeísta. Los libros de Caballero Calderón se ofrecían, por ampliar un ejemplo anterior, junto con los de notables escritores españoles, pero también con los de celebridades intelectuales internacionales como Arnold Hauser, Gaëtan Picon, Boris Pasternak y John Brown, este último traducido por el propio escritor colombiano.

Ejercicios de traducción como el asociado a Brown permiten, de hecho, ubicar a Caballero Calderón como un efímero actor de transferencia cultural en la España del periodo, dado que el trabajo de Brown, intitulado Panorama de la literatura norteamericana contemporánea (1956) y publicado originalmente en la colección "Le Point du Jour" de Gallimard, venía de ganar el Gran premio de la Crítica Literaria en Francia en 1954, galardón que lo convertía no solo en una sólida y novedosa propuesta antológica, sino en una singular ventana para los escritores españoles interesados en romper el represamiento cultural de su país y conocer las renovaciones literarias estadounidenses ${ }^{36}$.

La labor editorial de Caballero Calderón se aproxima así a la función del gatekeeper, un tipo particular de agente que, de acuerdo con la formulación de William Marling (2), se encarna en traductores o pequeños editores móviles entre dos o más culturas lingüísticas o nacionales, y cuya extendida actividad ayuda a explicar la configuración de una literatura mundial. La experiencia española del escritor, editor y también traductor colombiano permite analizarlo, inclusive, como un mediador cultural propiamente dicho. Ajustando la definición propuesta por Meylaerts y Roig-Sanz (3-4), Caballero Calderón fue un actor cultural activo a través de fronteras lingüísticas, culturales y geográficas, que ocupó posiciones estratégicas dentro de redes y propició transferencias culturales, todo a pesar de su transitorio ejercicio como editor y figura nodal transnacional.

El lugar desde el cual Caballero Calderón actuó editorialmente marca, no obstante, una notable diferencia con otros itinerarios latinoamericanos,

36 Sobre la importancia de los ejercicios de traducción y transferencia cultural en la historia del libro, véase asimismo el referido trabajo de Lyons y Mollier (10-12). 
especialmente en términos de internacionalización. Desde luego, Madrid distaba de ser un meridiano ideal para los escritores de la región, por lo que la elección del escritor - él mismo una suerte de exiliado de la dictadura de Rojas Pinilla- marcó una clara oposición frente a las miradas y expectativas más comunes, para las que la ruta parisina era ineludible. Como se ha mostrado, esta elección se basó en una razón personal, enlazada con su ferviente hispanismo, pero la misma anticipó, en cierto modo, la revalorización del espacio cultural español ocurrida una década más tarde y posibilitada por el vertiginoso ascenso de Barcelona como capital editorial del boom.

En conclusión, la experiencia de Caballero Calderón con Ediciones Guadarrama puede entenderse como un antecedente de importancia en la historia de uno de los episodios más relevantes de la historia de la literatura latinoamericana del siglo XX. A pesar de su condición de proyecto casi unipersonal, Guadarrama jugó como un puente editorial transatlántico, del mismo modo que lo hicieron colecciones como "Biblioteca Breve", "El Puente" o "Cimas de América", siendo la historia de su desarrollo una demostración de la existencia de caminos y capacidades de reconocimiento para los escritores latinoamericanos anteriores a la plena integración de la región a la república mundial de las letras.

\section{BIBLIOGRAFÍA}

Archivo General de la Administración (AGA), Instituto Nacional del Libro Español (INLE), Registro de Empresas Editoriales (REE), Ediciones Guadarrama, Caja 62/6441, expediente 8.

Bedoya, Luis Iván y Augusto Escobar. Colección conozca a: Eduardo Caballero Calderón. Medellín, Editorial Lealón, 1984.

Bourdieu, Pierre. "Les conditions sociales de la circulation internationale des idées". Actes de la recherche en sciences sociales 145, 2002, pp. 3-8.

“Caballero Calderón, novelista del 1lano”. La Hora 22, 6 de diciembre de 1956, p. 19.

Caballero Calderón, Eduardo. "Ventana sobre América. La editorial Losada". El Tiempo. Suplemento literario, 11 de noviembre 1951, p. 2.

Ancha es Castilla. Buenos Aires, Losada, 1954.

Carrillo Reveles, Veremundo. “'Las Américas', una historia de novelas. El concurso literario de la Unión Panamericana como instrumento diplomático". Revista de Historia de América 156, 2019, pp. 279-319.

Casanova, Pascale. La República mundial de las Letras. Barcelona, Anagrama, 2001. 
Catelli, Nora. "La élite itinerante del boom: seducciones transnacionales en los escritores latinoamericanos (1960-1973)". Historia de los intelectuales en América Latina. Carlos Altamirano y Jorge Myers (coord.), Buenos Aires, Katz, 2010, pp. 713-732.

De Glas, Frank. "The Literary Prize as an Instrument in the Material and Symbolic Production of Literature: The Case of the 'Prix Formentor', 1961-1965”. Quarendo 43, 2013, pp. 147-177.

“El premio a Swann". Revista de las Indias 51-52, marzo-abril 1943, 161.

English, JAmes F. The economy of prestige: prizes, awards, and the circulation of cultural value. Cambridge y Londres, Harvard University Press, 2005.

EspósITO, FABIO. "Seix Barral y el boom de la nueva narrativa hispanoamericana: las mediaciones culturales de la edición española". Orbis Tertius 14, N¹5, 2009, pp. 1-10.

FernÁNdez, Pura. "El monopolio del mercado internacional de impresos en castellano en el siglo XIX, Francia, España y "la ruta" de Hispanoamérica". Bulletin hispanique 100, $\mathrm{N}^{\circ} 1,1998$, pp. 165-190.

Gómez Restrepo, Antonio. “Acta de la Junta Pública del 23 de abril de 1942”. Discurso leído en el acto de su recepción por el señor don Eduardo caballero Calderón y Contestación del señor don Eduardo Guzmán Esponda. Bogotá, Biblioteca Nacional, 1944, pp. 7-9.

Guerrero, Gustavo, Jorge J. Locane, Benjamin Loy y Gesine Müller (eds.). Literatura latinoamericana mundial. Dispositivos y disidencias. Berlín y Boston, De Gruyter, 2020.

Gutiérrez Girardot, Rafael. Ensayos de literatura colombiana I. Medellín, Ediciones Unaula, 2011.

Heinich, Nathalie. De la visibilité. Excellence et singularité en régime médiatique. París, Éditions Gallimard, 2012.

Instituto Nacional del Libro Español. Los libros del año. Madrid, INLE, 1958.

“La Bibliografía en 1957”. Índice cultural 34, enero de 1958, s/p.

"Latin American literary contest prizewinners". Bulletin of the American Union 77, ํ7, julio de 1943, pp. 416-417.

"Libros de Ahora". Índice cultural, 1 de junio de 1952, pp. 22-23.

"Libros de Ahora". Índice cultural, 2 de julio-agosto de 1952, pp. 50-51.

"Libros y revistas". $A B C, 1$ de agosto 1954, pp. 43-44.

"Los libros mejor editados del año". $A B C, 17$ de diciembre de 1955, p. 47.

Lyons, Martyn y JeAn-Yves Mollier. "L'histoire du livre dans une perspective transnationale". Histoire et civilisation du livre 8, 2012, pp. 9-20.

Marling, William. Gatekeepers, the emergence of world literature and the 1960 's. Nueva York, Oxford University Press, 2016.

Martínez Martín, Jesús A. "La transición editorial. Los años setenta”. Historia de la edición en España 1939-1975. Jesús A. Martínez Martín (dir), Madrid, Marcial Pons Historia, 2015, pp. 329-386.

Martínez Rus, ANA. "La industria editorial española ante los mercados americanos del libro 1892-1936”. Hispania: revista española de Historia 62, N²12, 2002, pp. 1021-1058. 
Meylaerts, Reine y Diana Roig-Sanz. Literary Translation and Cultural Mediators in 'Peripheral' Cultures. Customs Officers or Smugglers? Londres, Palgrave Macmillan, 2018.

Nieto Caballero, L. E. Libros colombianos, segunda serie. Bogotá, Editorial Minerva, 1928.

Panero, Martín. "Neruda y España”. Taller de Letras 30, 2002 [1972], pp. 58-59.

Pohl, Burkhard. "Vender el boom: el discurso de la difusión editorial (1959-1975)". La llegada de los bárbaros. La recepción de la narrativa hispanoamericana en España (1967-1998). Eds. Joaquín Marco y Jordi Gracia. Barcelona, Edhasa, 2004, pp. 165-188.

Prat, José. "Las Ediciones de la Cruz del Sur". El Tiempo. Suplemento, 5 de diciembre de 1943, p. 1.

RAYMOND, PIERRE. Mucha tela que cortar: la saga de una fábrica textil y la pugna de las familias Caballero y López por su control. Bogotá, Planeta, 2008.

Rodrigo, Ana María. "Los organismos del libro y el corporativismo editorial: el Instituto Nacional del Libro Español”. Historia de la edición en España 1939-1975. Jesús A. Martínez Martín (dir.), Madrid, Marcial Pons, 2015, pp. 97-119.

Sanmiguel, Manuel. "Una editorial abierta a Europa y a América". El libro español. Revista mensual del Instituto Nacional del libro español 1, Nº7, 1958, pp. 331-333.

SAPIRO, Gisèle. "How Do Literary Works Cross Borders (or Not)? A Sociological Approach to World Literature". Journal of World Literature 1, N¹, 2016, pp. 81-96.

Souchier, EmmanuëL. "L'image du texte. Pour une théorie de l'énonciation éditoriale". Les Cahiers de médiologie 6, 1998, pp. 137-145.

Thérenty, Marie-Ėve. "Pour une poétique historique du support". Romantisme 143, №1, 2009, 109-115. 